\title{
A neurobehavioral account for decentering as the salve for the distressed mind
}

\author{
Anthony P. King \\ University of Michigan \\ David M. Fresco \\ Kent State University \\ Case Western Reserve University
}

Running head: Decentering from distress

Corresponding Author: Anthony King Department of Psychiatry, University of Michigan Medical School, 2747 Rachel Upjohn Building, 4250 Plymouth Rd, Ann Arbor, MI 48105 USA. Email: samadhi@med.umich.edu

Author Note: Anthony P. King was supported by National Institute of Mental Health Grant $1 \mathrm{~K} 23 \mathrm{MH} 112852$ and National Center for Complimentary and Integrative Health Grant 1R61AT009867. David M. Fresco was supported by National Heart, Lung, and Blood Institute Grant R01HL119977, National Institute of Nursing Research Grant P30NR015326, and National Center for Complimentary and Integrative Health Grant 1R61AT009867.

Keywords: distress, decentering, mindfulness-based interventions, intrinsic connectivity networks, cross-network connectivity 


\begin{abstract}
Distress is commonly characterized by prolonged internal suffering that can range from self-focused processing of negative emotions and stressors, to highly intensely aversive and prolonged emotional states thereby worsening or complicating emotional and physical conditions. Decentering represents a metacognitive capacity thought to reflect three interrelated processes: meta-awareness, disidentification from internal experience, and reduced reactivity to thought content-which is reliably increased with mindfulness-based interventions. In this essay, we seek to link the clinical presentation of distress disorders to known or hypothesized disruptions in neural networks that underlie emotion, cognition, and goal directed behavior, and offer a neurobehavioral account for how and why treatments imbued with mindfulness meditation might ameliorate these conditions, in part through increases in decentering.
\end{abstract}




\section{A neurobehavioral account for decentering as the salve for the distressed mind}

Distress is commonly characterized by prolonged internal suffering that can range from self-focused processing of negative emotions and stressors, to highly intensely aversive and prolonged emotional states [1, 2]. Distress typifies a set of psychiatric conditions including major depressive disorder (MDD), generalized anxiety disorder (GAD), and post-traumatic stress disorder (PTSD), which are highly prevalent, often comorbid with one another [3], and frequently treatment refractory $[4,5]$. Although expressing different constellations of symptoms, distress disorders also appear to share important underlying transdiagnostic characteristics that may contribute to the profound impairment, suffering, and treatment challenges [6]. For instance, distress disorders often exhibit intense emotionality [7-9] that affects both the experience of negative emotions as well as cognitive and behavioral factors that actually cause, worsen, and prolong the stressful situations they struggle to tolerate. This intense emotionality is often accompanied by negative self-referentiality including worry, rumination [6, 10], self-criticism [11], and loneliness [12, 13], which further complicates clinical presentation and treatment responsiveness [14].

Decentering represents a metacognitive capacity to observe items that arise in the mind (e.g., thoughts, feelings, memories) with healthy psychological distance, greater self-awareness and perspective-taking [15] and is thought to reflect three interrelated processes: metaawareness, disidentification from internal experience, and reduced reactivity to thought content [16]. Gains in decentering predict acute and enduring improvement in distress disorders following treatment with mindfulness-based interventions (MBIs) [17-20] as well as mindfulness enriched CBTs [21-24]. Theoretical accounts [16, 25, 26] and empirical findings [27, 
28] are beginning to reveal the neurobehavioral underpinnings of decentering and suggest MBIs lead to engagement and enduring alterations in large-scale neural networks associated with attention, executive control, and self-referential processing [29-31]. However, as the science of decentering continues to mature [32], more work is need to carefully elucidate how mindfulness acts on the distressed brain possibly via increases in decentering [20].

In this essay, we seek to identify known or hypothesized patterns of normative neural network function that are disrupted in MDD, GAD, and PTSD and that may underlie the decentering model of Bernstein and colleagues [16] and offer a neurobehavioral account for how and why treatments imbued with mindfulness meditation contribute to the effective and durable treatment of these conditions, in part through increasing a metacognitive capacity commonly known as decentering $[15,16]$.

Distributed Connectivity Networks in the Normative Human Brain

The human brain is functionally organized in distributed intrinsic connectivity networks that collectively, account for the majority of normative brain activity $[33,34]$. The Default Mode Network (DMN) refers to a reliable pattern of neural activity in the absence of a task, i.e. "at rest", and consists of nodes in the posterior cingulate cortex (PCC), ventral and dorsal medial prefrontal cortex (vmPFC, dmPFC), subgenual ACC (sgACC), precuneus, and temporal and lingual gyrus $[35,36]$. Computational fMRI work reveals functionally separable DMN subsystems [37, 38]: a "core" (PCC, vmPFC), associated with self-referentiality including the construction of a temporally-extended, static, "narrative self" [39, 40]; a medial temporal lobe (MTL) sub-system (vmPFC, hippocampus, parahippocampal gyrus, and inferior parietal lobule [IPL]), associated with episodic memories and self-prospection simulations ("mental time 
travel"); and a dorsomedial PFC (dmPFC) subsystem (dmPFC, temporoparietal junction [TPJ], and temporal pole), associated with metacognitive capacities including forms of psychological distancing, mentalizing, theory of mind, and other person perspective [37, 38].

Networks corresponding to task-related connectivity patterns underlie attention, cognitive control, and sensory processes [33, 34]. The Dorsal Attention Network (DAN, frontal eye field (FEF) and superior parietal lobule) underlies volitional deployment of attention toward stimuli and externally-directed cognitions, the Ventral Attention Network (VAN, inferior frontal gyrus (IFG)/ventrolateral PFC (vIPFC) and middle temporal gyrus (MTG)), is involved in relatively automatic orientation to unexpected events. The Salience Network (SN, dorsal anterior cingulate (dACC), insula, and amygdala) [41], is associated with detection of salience and threat in the environment $[42,43]$ and error detection between flows of information. SN activation can move attention away from spontaneous internal thoughts and toward "salient" external stimuli, integrating sensory, emotional, and cognitive information to facilitate optimal communication, social behavior, and self-awareness [41]. The Frontoparietal Control Network (FPCN, bilateral dIPFC and posterior parietal cortex (PPC)), is involved in executive functions and "top-down control", as well as monitoring moment-to-moment coordination between attention, sensory, and internal networks, regulating and directing distributed systems according to current task goals [44].

Increasing evidence indicates distress disorders exhibit aberrant patterns of within- and between-network connectivity [45-49] including decreased activity and within-network connectivity in the FPCN, and FPCN-DAN connectivity, that may underlie cognitive and concentration deficits. GAD and PTSD show hyperactivity and hyperconnectivity with the SN, 
likely underlying increased somatic anxiety and hyperarousal. MDD and GAD show increased DMN activity and connectivity, which may underlie negative rumination and worry, whereas PTSD shows decreased DMN and increased SN-DMN hyperconnectivity, which may underlie intrusion of hypervigilance into resting awareness [45, 46, 50, 51].

Effects of mindfulness on proposed metacognitive processes in decentering

Establishing a mindfulness practice leads to increased capacity for decentering [17-20] as well as reliable and enduring alterations in the basal neural activity and connectivity, which may account for clinical improvement associated with MBIs [46, 52, 53]. Accumulating evidence offers indications for functional patterns of brain network configurations reflected in the proposed decentering components [16] that may contribute to the resolution of distress disorders $[54,55]$.

Meta-Awareness. Meta-awareness reflects awareness of one's subjective experience and the processes of sensing, feeling, and thinking [16] and requires both volitional control of attention, as well the ability to identify and inhibit spontaneous evaluative processes. Mindfulness practices often facilitate meta-awareness through sustained, volitional attention to bodily sensations. Initially, considerable effort is required both to retain focus on the body sensations, and to "monitor" and become aware of when one is not attending to sensation and/or when attention is drifting into spontaneously generated internal thoughts (mediated by DMN) [56]. Volitional attention to external stimuli is mediated by DAN, often in coordination with FPCN, whereas attending to bodily sensations (and interoception in particular) is also expected to engage activity in the insula, an important node of the SN $[26,29,56]$. Detecting moments of not attending to one's object during meditation, and 
spontaneous internal thoughts and mind-wandering generated by DMN (i.e. a form of error detection) is expected to engage SN, in particular dACC and insula [29, 31]. The subsequent moving of attention away from internal thoughts (and back to the body sensations) likely involves SN-mediated shifting of connectivity of FPCN away from DMN and toward DAN $[29,31]$.

Similarly, repeated practice of mindfulness meditation leads to enduring increases in baseline activity and connectivity (i.e. when not meditating) of SN and attention networks in formerly meditation-naïve people [57], which may underlie increased capacity for meta-awareness in daily life. Numerous MBI-linked fMRI findings report increased basal activity in SN including the dACC and insula $[56,58]$, increased white matter structural connectivity in dACC $[59,60]$, increased network efficiency of dACC [61], increased functional connectivity in SN [62], structural connectomic reorganization of right anterior insula [63], and enhanced EEG fronto-central theta synchrony following MBCT [64], suggesting increased dACC activity

MBIs also lead to enduring changes in FPCN and DAN, including increased activity in FPCN (dIPFC and posterior parietal cortex [PPC]) during executive processing [65] and emotion regulation tasks [66] following MBSR. Three-days of intensive meditation produced increased connectivity between FPCN, DAN, and VAN [67]. Taken together, these findings suggest MBIs may lead to enduring increases in activity and/or coordination of SN, FPCN, and DAN that possibly underlie increased capacity for meta-awareness of and disengagement with spontaneous internal thoughts and shifting attention toward presentmoment physical sensations [31]. 
Disidentification. Disidentification refers to the capacity for creating psychological distance from internal states, thereby helping individuals regard thoughts, emotions, and sensations as passing mental phenomena as not necessarily true and not necessarily identical to one's self [16]. Disidentification is perhaps epitomized by the slogan "Don't believe everything you think". All humans spend considerable time mind-wandering in a self-immersed state experiencing spontaneous internal thoughts such as self-appraisals of the static self, when not addressing other neural and physical demands [68]. Selfimmersed mentation is especially associated with the "core" DMN (PCC and vmPFC) and other mPFC regions $[39,69,70]$. Aberrant DMN activity has been linked to depressive rumination [71] and although not universally maladaptive, many forms of psychiatric disorder are marked by hyperactivity in DMN [72], which can delay or interfere with purposeful activation of neural regions associated with executive control [72], undermining cognitive load and emotion regulation capacities $[72,73]$, further impairing emotional control in the face of negative self-referentiality. MDD, GAD, and PTSD are all associated with deficits in executive control, and weakened FPCN and FPCN connectivity with attention networks [46, 47, 74, 75].

The attentional focus on internal thoughts practiced in mindfulness suggest disidentification may involve dynamic modulation or regulation of spontaneous DMN activity by executive control and attentional processes. Several studies of acute practice of mindfulness meditation and laboratory analogues report decreased connectivity in "core" DMN (PCC-vmPFC) activity and connectivity in meditation-naïve people $[39,76,77]$ and more pronounced decreases in DMN occur when instructed to meditate following a course 
of MBSR [39] and among long-term meditators [73, 77]. Decreased basal levels (when not meditating) of core DMN connectivity are also reported in long-term meditators [76, 78], which may reflect the enduring neurobehavioral effects of mindfulness. Recent reports of mindfulness-linked increases in enduring cross-network connectivity between $\mathrm{DMN}$ and FPCN might be related to changes in executive control in mindfulness. Several independent groups report increased connectivity between PCC and dIPFC, in healthy people $[76,79]$ and in psychiatric patients with anxious depression [27] and PTSD [80], suggesting MBIs may lead to increased access to executive attention networks during mind-wandering. Greater DMN-FPCN (PCC-dIPFC) connectivity following MBI was associated with greater clinical improvement in PTSD symptoms [80], suggesting it could be linked to a therapeutic mechanism; decreased connectivity between anterior DMN and FPCN (dIPFC) has been related to greater severity of PTSD symptoms [81]. MBIs and longterm meditation are also associated with increased connectivity between the dIPFC (FPCN) and insula (SN) during self-referential processing [39], and increased PCC (DMN) and dACC (SN) during rest / mind-wandering [76, 80].

Although speculative, taken together, these early findings are suggestive of a mindfulness-entrained brain network configuration characterized by coordinated increased within-network connectivity in FPCN (73) and SN [67] increased cross-network connectivity in FPCN-DMN $[27,76,79,80]$ and FPCN-DAN [67], and altered patterns of cross-network connectivity between DMN and SN [39, 76, 80]. Such altered coordination between attention and executive control networks and DMN by MBIs might underlie increased capacity for meta-awareness and disidentification, and thereby improved top-down control 
of spontaneous negative internal self-related thoughts, greater capacity for disengagement with negatively-biased internal thoughts, and greater flexibility of shifting attention [31, 82, 83], thereby decreasing susceptibility to perceptual decoupling and less "stickiness" of negative rumination.

Disidentification might also reflect altered patterns of function in DMN subsystems. Spontaneous self-related thought processes particularly relevant to distress disorders such as autobiographical memories and negative future self-prospections (e.g., distressing or catastrophic) involve the MTL-DMN and dmPFC-DMN subsystems. Whereas autobiographical memory retrieval is associated with the hippocampal MTL-DMN subsystem, metacognition or "mentalizing" of autobiographical memories leads to greater involvement of the dmPFC-DMN subsystem [37, 84], suggesting the dmPFC-DMN subsystem might contribute to disidentification. Consistent with this speculation, MBIinduced alterations reported in the dmPFC-DMN subsystem include increased connectivity of dmPFC with posterior DMN [62, 85], increased dmPFC-IPL connectivity [78], and increased dmPFC-insula anti-correlation [86]. Long-term meditation and MBIs also appear to lead to enduring alterations in the MTL-DMN, including greater hippocampal grey matter density [52, 87-89] and increased resting connectivity between hippocampus and PCC [85]. These findings suggest the possibility that MBI-induced changes in these DMN subsystems could be involved in increased capacity for disidentification to spontaneously generated painful autobiographic memories or catastrophic self-projections.

Reduced reactivity. The psychological distancing in disidentification is proposed to facilitate reduced reactivity to negative thoughts so that they are less likely to trigger 
stronger negative emotional reactions and negative self-conscious or depressive rumination. Improved meta-awareness of spontaneous negative thoughts that could trigger a cycle of rumination or worry, used in conjunction with increased capacity for disidentification, might underlie the ability of MBIs to decrease negative rumination in people with distress disorder $[64,83,90,91]$. Increased capacity to more flexibly refocus attention away from negative internal thoughts and toward a broader awareness of present-moment external and interoceptive stimuli may also lead to greater opportunities to connect with contemporaneous pleasure/reward and increased positive reappraisals [92]. We hypothesize coordinated network connectivity between FPCN, DAN, and DMN might facilitate disidentification from negative self-related thoughts and improved topdown control of emotional responses.

Aberrant within-network and between network connectivity in the SN is implicated in intense negative emotionality and can amplify somatosensory and interoceptive awareness of physiological cues, potentially underlying hypervigilance. Although commonly associated with positive health outcomes [93], greater interoceptive awareness also predicts increased anxiety and panic, especially when one's bodily sensations are catastrophized [94-98] or when engaging in negative self-referentiality [96, 97]. Negative self-referentiality appears to exaggerate arousal (i.e., positive or negative) and increases the likelihood that such cues are interpreted negatively, resulting in increased sympathetic arousal, and increased escape or avoidance behaviors [97]. Hyperactivity of insula, dACC, and amygdala is widely seen in PTSD and GAD [45, 99-101]. MDD and GAD consistently show that hyperactivity of the anterior insula is often accompanied by increased connectivity with nodes of DMN including the PCC $[97,102,103]$ and 
mPFC [47]. PTSD is associated with hyperconnectivity within the SN, in particular heightened insula-amygdala and insula-dACC connectivity $[45,51]$ as well as hyperconnectivity between insula and DMN nodes [104] that is thought to underlie hyperarousal symptoms.

Mindfulness is associated with decreased subjective emotional reactions and decreased amygdala (a key node of SN) responses to negative self-related or social stimuli in laboratory paradigms with meditation-naïve individuals $[105,106]$, in healthy people [107], in MBI patients [39, 108, 109], and in long-term meditators [110]. Similarly, mindfulness tasks [111] and MBIs increase top-down regulation of emotional amygdala responses by increased amygdala connectivity or coordination with vmPFC [110], ventrolateral PFC (vIPFC) [109], and left fronto-parietal network [111]; suggesting increased frontal-amygdala integration as a potential neural mechanism of emotional regulation increased by MBIs. Similarly, a 3-day intensive mindfulness intervention led to decreased sgACC (DMN node) resting connectivity with amygdala suggesting another related potential mechanism underlying decreased reactivity to internal thoughts [112].

Mindfulness meditation has been proposed to reflect a form of exposure to feared and distressing spontaneous thoughts and internal experiences leading to decreased subjective and neural reactivity [57, 113-115]. MBI-related changes occur in the same limbic and orbitofrontal/prefrontal regions $[52,87-89,115]$ underlying fear conditioning, extinction, and extinction recall $[50,100,116]$. One study reports MBSR increased fear conditioning as well as extinction learning, and also increased structural connectivity (fractional anisotropy) with the uncinate fasciculus, a fiber tract involved in emotional regulation and associative learning [113]. The MTL-DMN subsystem contains the vmPFC- 
hippocampal circuits involved in contextual modulation of conditioned fear and extinction recall, and processes of pattern completion and pattern separation crucial for appropriate contextual responses to learned fear $[50,117]$. The present-moment, sensory focus of mindfulness practice appears to be a form of "contextualizing" oneself in time and space (now and here), and better differentiating between one's present-moment sensory experiences vs. one's thoughts, autobiographic memories, and future prospections.

Although increased engagement of SN during mindfulness practice and enduring increases in SN connectivity following MBIs may improve one's capacity to disengage from internal thoughts such as rumination, worry, and distressing memories, $\mathrm{SN}$ is already hyperactive in anxiety disorders and PTSD [99], and aberrant cross-network connectivity between SN and DMN appears to play a role in driving distress in these disorders [97, 104]. Sustained attention to interoceptive processes during mindfulness practice in patients with anxiety or PTSD may provide important additional forms of exposure to feared interoceptive cues and negative internal thoughts and interpretations (i.e., as seen in the phenomena of "relaxation induced anxiety"[118]) potentially leading to habituation and decreased reactivity, as well as more accurate interpretations of such stimuli. These observed alterations in patterns between-network connectivities between SN, FPCN, and DMN following MBIs may underlie habituation and improved top-down regulation of these internal experiences.

\section{Summary}

In this paper, we reviewed known or hypothesized neural correlates of how the practice of mindfulness meditation may increase one's ability for decentering, especially in 
relation to neural networks implicated in distress disorders. Although the state of the literature is preliminary, MBI-related alterations including increased within-network connectivity in SN and FPCN and increased coordination of FPCN with attention networks are consistent with increased capacity for meta-awareness. It seems plausible that disidentification from internal thoughts may involve modulation of spontaneous DMN activity by attentional and executive processes, possibly reflected by altered betweennetwork DMN connectivity with FPCN and SN and/or alteration in DMN subsystems. Despite progress in better understanding the distressed brain and the potential ameliorative effects of MBIs, questions remain yet also point to some important future directions. For instance, further work is needed to better differentially examine psychological components of the practice of mindfulness and decentering (e.g. metaawareness vs. disidentification) [29, 119] within neuroimaging paradigms, to better understand their specific functional neurocircuitry. An important future direction will be to delineate whether MBI-linked changes in connectivity patterns may provide the neural basis for decreased identification with and emotional reactivity to spontaneously generated negative episodic memories in PTSD and depression, and negative or catastrophic future prospections that are central features of disorders of distress [46, 115]. Future work might examine the effects of MBIs on the neurocircuitry of contextual processing in disorders of distress, and in particular the deficits in contextual processing circuitry seen in PTSD [50]. Finally, we have based this account of mindfulness meditation linked gains in relation to the conceptual model of decentering posited by Bernstein and colleagues [16] which is but one of several contemporary models $[26,57,114]$ and treatment packages [120-122] that 
offer account for how practice of mindfulness leads to greater well-being. An important future direction will be to thoughtfully compare and synthesize all these models into a more comprehensive understanding of the salutary benefits of mindfulness meditation. 


\section{References}

1. Brosschot JF, Verkuil B, Thayer JF: Generalized Unsafety Theory of Stress: Unsafe Environments and Conditions, and the Default Stress Response. International Journal of Environmental Research and Public Health 2018, 15(3):464.

2. Mennin DS, Fresco DM: Advancing Emotion Regulation Perspectives on Psychopathology: The Challenge of Distress Disorders. Psychological Inquiry 2015, 26(1):80-92.

3. Kessler RC, Berglund P, Demler O, Jin R, Merikangas KR, Walters EE: Lifetime Prevalence and Age-of-Onset Distributions of DSM-IV Disorders in the National Comorbidity Survey Replication. Archives of General Psychiatry 2005, 62(6):593-602-602.

4. Farabaugh A, Alpert J, Wisniewski SR, Otto MW, Fava M, Baer L, Perlis R, Friedman E, Nyer M, Bitran S et al: Cognitive therapy for anxious depression in STAR*D: What have we learned? Journal of Affective Disorders 2012, 142(1-3):213-218.

5. Farabaugh AH, Bitran S, Witte J, Alpert J, Chuzi S, Clain AJ, Baer L, Fava M, McGrath PJ, Dording $C$ et al: Anxious depression and early changes in the HAMD-17 anxietysomatization factor items and antidepressant treatment outcome. International Clinical Psychopharmacology 2010, 25(4):214.

6. Mennin DS, Fresco DM: What, Me Worry and Ruminate About DSM-5 and RDoC? The Importance of Targeting Negative Self-Referential Processing. Clinical Psychology: Science and Practice 2013, 20(3):258-267.

7. Barlow DH, Ellard KK, Sauer-Zavala S, Bullis JR, Carl JR: The Origins of Neuroticism. Perspectives on Psychological Science 2014, 9(5):481-496.

8. Mineka S, Watson D, Clark LA: Comorbidity of anxiety and unipolar mood disorders. Annual Review of Psychology 1998, 49(1):377-412.

9. Shackman AJ, Tromp DPM, Stockbridge MD, Kaplan CM, Tillman RM, Fox AS: Dispositional negativity: An integrative psychological and neurobiological perspective. Psychological Bulletin 2016, 142(12):1275.

10. Ottaviani C, Thayer JF, Verkuil B, Lonigro A, Medea B, Couyoumdjian A, Brosschot JF: Physiological Concomitants of Perseverative Cognition: A Systematic Review and Meta-Analysis. Psychological Bulletin 2015, 142(3):231-259.

11. Blatt SJ: The destructiveness of perfectionism: Implications for the treatment of depression. American Psychologist 1995, 50(12):1003-1020.

12. Cacioppo S, Grippo AJ, London S, Goossens L, Cacioppo JT: Loneliness: Clinical Import and Interventions. Perspectives on Psychological Science 2015, 10(2):238-249.

13. Eisenberger NI, Cole SW: Social neuroscience and health: neurophysiological mechanisms linking social ties with physical health. Nature Neuroscience 2012, 15(5):669-674.

14. Olatunji BO, Cisler JM, Tolin DF: A meta-analysis of the influence of comorbidity on treatment outcome in the anxiety disorders. Clinical Psychology Review 2010, 30(6):642-654-654.

15. Fresco DM, Moore M, T., van Dulmen M, H. M., Segal Z, V., Ma SH, Teasdale J, D. , Williams JMG: Initial Psychometric Properties of the Experiences Questionnaire: 
Validation of a Self-Report Measure of Decentering. Behavior Therapy 2007, 38(3):234246.

16. Bernstein A, Hadash Y, Lichtash Y, Tanay G, Shepherd K, Fresco DM: Decentering and Related Constructs: A Critical Review and Metacognitive Processes Model.

Perspectives on Psychological Science 2015, 10(5):599-617.

17. Bieling PJ, Hawley LL, Bloch RT, Corcoran KM, Levitan RD, Young TL, MacQueen GM, Segal ZV: Treatment-specific changes in decentering following mindfulness-based cognitive therapy versus antidepressant medication or placebo for prevention of depressive relapse. Journal of Consulting and Clinical Psychology 2012, 80(3):365.

18. Farb N, Anderson A, Ravindran A, Hawley L, Irving J, Mancuso E, Gulamani T, Williams G, Ferguson A, Segal ZV: Prevention of Relapse/Recurrence in Major Depressive Disorder With Either Mindfulness-Based Cognitive Therapy or Cognitive Therapy. Journal of Consulting and Clinical Psychology 2017.

19. Hoge EA, Bui E, Goetter E, Robinaugh DJ, Ojserkis RA, Fresco DM, Simon NM: Change in Decentering Mediates Improvement in Anxiety in Mindfulness-Based Stress Reduction for Generalized Anxiety Disorder. Cognitive Therapy and Research 2015, 39(2):228-235.

20. Segal ZV, Anderson AK, Gulamani T, Williams L-AD, Desormeau P, Ferguson A, Walsh K, Farb NAS: Practice of therapy acquired regulatory skills and depressive relapse/recurrence prophylaxis following cognitive therapy or mindfulness based cognitive therapy. Journal of Consulting and Clinical Psychology 2018.

21. Fresco DM, Roy AK, Adelsberg S, Seeley S, García-Lesy E, Liston C, Mennin DS: Distinct Functional Connectivities Predict Clinical Response with Emotion Regulation Therapy. Frontiers in Human Neuroscience 2017, 11:86.

22. Hayes-Skelton SA, Calloway A, Roemer L, Orsillo SM: Decentering as a Potential Common Mechanism Across Two Therapies for Generalized Anxiety Disorder. Journal of consulting and clinical psychology 2014, 83(2):395-404.

23. Mennin DS, Fresco DM, O'Toole MS, Heimberg RG: A Randomized Controlled Trial of Emotion Regulation Therapy for Generalized Anxiety Disorder With and Without CoOccurring Depression. Journal of Consulting and Clinical Psychology 2018.

24. Mennin DS, Fresco DM, Ritter M, Heimberg RG: An open trial of Emotion Regulation Therapy For generalized anxiety disorder with co-occurring depression. Depression and Anxiety 2015, 32(8):614-623.

25. Bendall RCA, Royle S: Decentering mediates the relationship between vmPFC activation during a stressor and positive emotion during stress recovery. Journal of Neurophysiology 2018.

26. Vago DR, Silbersweig DA: Self-awareness, self-regulation, and self-transcendence (SART): a framework for understanding the neurobiological mechanisms of mindfulness. Frontiers in Human Neuroscience 2012, 6:296.

27. Scult MA, Fresco DM, Gunning FM, Liston C, Seeley SH, Garcia E, Mennin DS: Changes in Functional Connectivity following Treatment with Emotion Regulation Therapy. . Frontiers in Behavioral Neuroscience 2019.

28. Yang X, Garcia K, Jung Y, Whitlow CT, McRae K, Waugh CE: VMPFC activation during a stressor predicts positive emotions during stress recovery. Social Cognitive and Affective Neuroscience 2018:nsy012. 
29. Hasenkamp W, Barsalou LW: Effects of meditation experience on functional connectivity of distributed brain networks. Front Hum Neurosci 2012, 6:38.

30. Tang YY, Tang Y, Tang R, Lewis-Peacock JA: Brief Mental Training Reorganizes LargeScale Brain Networks. Front Syst Neurosci 2017, 11:6.

31. Vago DR, Zeidan F: The brain on silent: mind wandering, mindful awareness, and states of mental tranquility. Ann N Y Acad Sci 2016, 1373(1):96-113.

32. Bernstein A, Hadash Y, Fresco DM: Metacognitive Processes Model of Decentering: Emerging Methods and Insights Current Opinion in Psychology in press.

33. Fox MD, Snyder AZ, Vincent JL, Corbetta M, Van Essen DC, Raichle ME: The human brain is intrinsically organized into dynamic, anticorrelated functional networks. Proc Natl Acad Sci U S A 2005, 102(27):9673-9678.

34. Yeo BT, Krienen FM, Sepulcre J, Sabuncu MR, Lashkari D, Hollinshead M, Roffman JL, Smoller JW, Zollei L, Polimeni JR et al: The organization of the human cerebral cortex estimated by intrinsic functional connectivity. J Neurophysiol 2011, 106(3):1125-1165.

35. Raichle ME: The brain's default mode network. Annu Rev Neurosci 2015, 38:433-447.

36. Raichle ME, MacLeod AM, Snyder AZ, Powers WJ, Gusnard DA, Shulman GL: A default mode of brain function. Proc Natl Acad Sci U S A 2001, 98(2):676-682.

37. Andrews-Hanna JR, Reidler JS, Sepulcre J, Poulin R, Buckner RL: Functional-anatomic fractionation of the brain's default network. Neuron 2010, 65(4):550-562.

38. Andrews-Hanna JR, Smallwood J, Spreng RN: The default network and self-generated thought: component processes, dynamic control, and clinical relevance. Ann N Y Acad Sci 2014, 1316:29-52.

39. Farb NA, Segal ZV, Mayberg H, Bean J, McKeon D, Fatima Z, Anderson AK: Attending to the present: mindfulness meditation reveals distinct neural modes of self-reference. Soc Cogn Affect Neurosci 2007, 2(4):313-322.

40. Watkins E, Teasdale JD: Rumination and overgeneral memory in depression: effects of self-focus and analytic thinking. J Abnorm Psychol 2001, 110(2):353-357.

41. Menon V: Salience Network. In: Brain Mapping: An Encyclopedic Reference. Volume 2, edn. Edited by Arthur W. Toga: Academic Press: Elsevie; 2015: 597-611.

42. Breukelaar IA, Antees C, Grieve SM, Foster SL, Gomes L, Williams LM, Korgaonkar MS: Cognitive control network anatomy correlates with neurocognitive behavior: $A$ longitudinal study. Hum Brain Mapp 2017, 38(2):631-643.

43. Cole MW, Schneider W: The cognitive control network: Integrated cortical regions with dissociable functions. Neuroimage 2007, 37(1):343-360.

44. Cole MW, Repovs G, Anticevic A: The frontoparietal control system: a central role in mental health. Neuroscientist 2014, 20(6):652-664.

45. Akiki TJ, Averill CL, Abdallah CG: A Network-Based Neurobiological Model of PTSD: Evidence From Structural and Functional Neuroimaging Studies. Curr Psychiatry Rep 2017, 19(11):81.

46. Boyd JE, Lanius RA, McKinnon MC: Mindfulness-based treatments for posttraumatic stress disorder: a review of the treatment literature and neurobiological evidence. $J$ Psychiatry Neurosci 2018, 43(1):7-25. 
47. Kaiser RH, Andrews-Hanna JR, Wager TD, Pizzagalli DA: Large-Scale Network Dysfunction in Major Depressive Disorder: A Meta-analysis of Resting-State Functional Connectivity. JAMA Psychiatry 2015, 72(6):603-611.

48. Andreescu C, Sheu LK, Tudorascu D, Walker S, Aizenstein H: The ages of anxietydifferences across the lifespan in the default mode network functional connectivity in generalized anxiety disorder. International Journal of Geriatric Psychiatry 2014, 29(7):704-712.

49. Wang W, Hou J, Qian S, Liu K, Li B, Li M, Peng Z, Xin K, Sun G: Aberrant regional neural fluctuations and functional connectivity in generalized anxiety disorder revealed by resting-state functional magnetic resonance imaging. Neuroscience Letters 2016, 624:78-84.

50. Liberzon I, Abelson JL: Context Processing and the Neurobiology of Post-Traumatic Stress Disorder. Neuron 2016, 92(1):14-30.

51. Sripada RK, Garfinkel SN, Liberzon I: Avoidant symptoms in PTSD predict fear circuit activation during multimodal fear extinction. Front Hum Neurosci 2013, 7:672.

52. Gotink RA, Meijboom R, Vernooij MW, Smits M, Hunink MG: 8-week Mindfulness Based Stress Reduction induces brain changes similar to traditional long-term meditation practice - A systematic review. Brain Cogn 2016, 108:32-41.

53. Tomasino B, Fregona S, Skrap M, Fabbro F: Meditation-related activations are modulated by the practices needed to obtain it and by the expertise: an ALE metaanalysis study. Front Hum Neurosci 2012, 6:346.

54. Fresco DM, Mennin DS: All together now: Utilizing common functional change principles to unify cognitive behavioral and mindfulness-based therapies. Current Opinion in Psychology 2018.

55. Mennin DS, Ellard KK, Fresco DM, Gross JJ: United We Stand: Emphasizing Commonalities Across Cognitive-Behavioral Therapies. Behavior Therapy 2013, 44(2):234-248.

56. Tang YY, Lu Q, Feng H, Tang R, Posner MI: Short-term meditation increases blood flow in anterior cingulate cortex and insula. Front Psychol 2015, 6:212.

57. Tang YY, Holzel BK, Posner MI: The neuroscience of mindfulness meditation. Nat Rev Neurosci 2015, 16(4):213-225.

58. Haase L, May AC, Falahpour M, Isakovic S, Simmons AN, Hickman SD, Liu TT, Paulus MP: A pilot study investigating changes in neural processing after mindfulness training in elite athletes. Front Behav Neurosci 2015, 9:229.

59. Tang YY, Lu Q, Geng X, Stein EA, Yang Y, Posner MI: Short-term meditation induces white matter changes in the anterior cingulate. Proc Natl Acad Sci U S A 2010, 107(35):15649-15652.

60. Tang YY, Lu Q, Fan M, Yang Y, Posner MI: Mechanisms of white matter changes induced by meditation. Proc Natl Acad Sci U S A 2012, 109(26):10570-10574.

61. Xue S, Tang YY, Posner MI: Short-term meditation increases network efficiency of the anterior cingulate cortex. Neuroreport 2011, 22(12):570-574.

62. Kilpatrick LA, Suyenobu BY, Smith SR, Bueller JA, Goodman T, Creswell JD, Tillisch K, Mayer EA, Naliboff BD: Impact of Mindfulness-Based Stress Reduction training on intrinsic brain connectivity. Neuroimage 2011, 56(1):290-298. 
63. Sharp PB, Sutton BP, Paul EJ, Sherepa N, Hillman CH, Cohen NJ, Kramer AF, Prakash RS, Heller W, Telzer EH et al: Mindfulness training induces structural connectome changes in insula networks. Sci Rep 2018, 8(1):7929.

64. Schoenberg PLA, Speckens AEM: Modulation of induced frontocentral theta (Fm- $\theta)$ event-related (de-)synchronisation dynamics following mindfulness-based cognitive therapy in Major Depressive Disorder. 2014, 8(5):373-388-388.

65. Allen M, Dietz M, Blair KS, van Beek M, Rees G, Vestergaard-Poulsen P, Lutz A, Roepstorff $A$ : Cognitive-affective neural plasticity following active-controlled mindfulness intervention. J Neurosci 2012, 32(44):15601-15610.

66. Goldin PR, Gross JJ: Effects of mindfulness-based stress reduction (MBSR) on emotion regulation in social anxiety disorder. Emotion 2010, 10(1):83-91.

67. Taren AA, Gianaros PJ, Greco CM, Lindsay EK, Fairgrieve A, Brown KW, Rosen RK, Ferris $\mathrm{JL}$, Julson E, Marsland AL et al: Mindfulness Meditation Training and Executive Control Network Resting State Functional Connectivity: A Randomized Controlled Trial. Psychosom Med 2017.

68. Killingsworth MA, Gilbert DT: A Wandering Mind Is an Unhappy Mind. 2010, 330(6006):932-932-932.

69. Northoff G, Bermpohl F: Cortical midline structures and the self. Trends Cogn Sci 2004, 8(3):102-107.

70. Northoff G, Heinzel A, de Greck M, Bermpohl F, Dobrowolny H, Panksepp J: Selfreferential processing in our brain--a meta-analysis of imaging studies on the self. Neuroimage 2006, 31(1):440-457.

71. Hamilton JP, Farmer M, Fogelman P, Gotlib IH: Depressive Rumination, the DefaultMode Network, and the Dark Matter of Clinical Neuroscience. 2015, 78(4):224-230230.

72. Whitfield-Gabrieli S, Ford JM: Default Mode Network Activity and Connectivity in Psychopathology. Annual Review of Clinical Psychology 2012, 8(1):49-76.

73. Brewer JA, Worhunsky PD, Gray JR, Tang Y-Y, Weber J, Kober H: Meditation experience is associated with differences in default mode network activity and connectivity. Proceedings of the National Academy of Sciences 2011, 108(50):20254-20259.

74. Akiki TJ, Averill CL, Wrocklage KM, Scott JC, Averill LA, Schweinsburg B, Alexander-Bloch A, Martini B, Southwick SM, Krystal JH et al: Default mode network abnormalities in posttraumatic stress disorder: A novel network-restricted topology approach. Neuroimage 2018, 176:489-498.

75. Sylvester CM, Corbetta M, Raichle ME, Rodebaugh TL, Schlaggar BL, Sheline YI, Zorumski $\mathrm{CF}$, Lenze EJ: Functional network dysfunction in anxiety and anxiety disorders. Trends Neurosci 2012, 35(9):527-535.

76. Brewer JA, Worhunsky PD, Gray JR, Tang YY, Weber J, Kober H: Meditation experience is associated with differences in default mode network activity and connectivity. Proc Natl Acad Sci U S A 2011, 108(50):20254-20259.

77. Lutz J, Bruhl AB, Scheerer H, Jancke L, Herwig U: Neural correlates of mindful selfawareness in mindfulness meditators and meditation-naive subjects revisited. Biol Psychol 2016, 119:21-30. 
78. Taylor VA, Daneault V, Grant J, Scavone G, Breton E, Roffe-Vidal S, Courtemanche J, Lavarenne AS, Marrelec G, Benali $\mathrm{H}$ et al: Impact of meditation training on the default mode network during a restful state. Soc Cogn Affect Neurosci 2013, 8(1):4-14.

79. Creswell JD, Taren AA, Lindsay EK, Greco CM, Gianaros PJ, Fairgrieve A, Marsland AL, Brown KW, Way BM, Rosen RK et al: Alterations in Resting-State Functional Connectivity Link Mindfulness Meditation With Reduced Interleukin-6: A Randomized Controlled Trial. Biol Psychiatry 2016, 80(1):53-61.

80. King AP, Block SR, Sripada R, Rauch SA, Giardino ND, Favorite T, Angstadt M, Liberzon I: Altered Default Mode Network (DMN) Resting State Functional Connectivity Following a Mindfulness-based Exposure Therapy for Posttraumatic Stress Disorder (PTSD) in Combat Veterans of Afghanistan and Iraq. Depression and Anxiety 2016, in press.

81. Clausen AN, Francisco AJ, Thelen J, Bruce J, Martin LE, McDowd J, Simmons WK, Aupperle RL: PTSD and cognitive symptoms relate to inhibition-related prefrontal activation and functional connectivity. Depress Anxiety 2017, 34(5):427-436.

82. Dixon ML, Andrews-Hanna JR, Spreng RN, Irving ZC, Mills C, Girn M, Christoff K: Interactions between the default network and dorsal attention network vary across default subsystems, time, and cognitive states. Neuroimage 2017, 147:632-649.

83. Schoenberg PL, Speckens AE: Multi-dimensional modulations of alpha and gamma cortical dynamics following mindfulness-based cognitive therapy in Major Depressive Disorder. Cogn Neurodyn 2015, 9(1):13-29.

84. Andrews-Hanna JR, Saxe R, Yarkoni T: Contributions of episodic retrieval and mentalizing to autobiographical thought: evidence from functional neuroimaging, resting-state connectivity, and fMRI meta-analyses. Neuroimage 2014, 91:324-335.

85. Wells RE, Yeh GY, Kerr CE, Wolkin J, Davis RB, Tan Y, Spaeth R, Wall RB, Walsh J, Kaptchuk TJ et al: Meditation's impact on default mode network and hippocampus in mild cognitive impairment: a pilot study. Neurosci Lett 2013, 556:15-19.

86. Farb NA, Segal ZV, Anderson AK: Mindfulness meditation training alters cortical representations of interoceptive attention. Soc Cogn Affect Neurosci 2013, 8(1):15-26.

87. Luders E, Thompson PM, Kurth F, Hong JY, Phillips OR, Wang Y, Gutman BA, Chou YY, Narr KL, Toga AW: Global and regional alterations of hippocampal anatomy in longterm meditation practitioners. Hum Brain Mapp 2013, 34(12):3369-3375.

88. Greenberg J, Romero VL, Elkin-Frankston S, Bezdek MA, Schumacher EH, Lazar SW: Reduced interference in working memory following mindfulness training is associated with increases in hippocampal volume. Brain Imaging Behav 2018.

89. Holzel BK, Carmody J, Vangel M, Congleton C, Yerramsetti SM, Gard T, Lazar SW: Mindfulness practice leads to increases in regional brain gray matter density. Psychiatry Res 2011, 191(1):36-43.

90. Batink T, Peeters F, Geschwind N, van Os J, Wichers M: How does MBCT for depression work? studying cognitive and affective mediation pathways. PLoS One 2013, 8(8):e72778.

91. Shahar B, Britton WB, Sbarra DA, Figueredo AJ, Bootzin RR: Mechanisms of Change in Mindfulness-Based Cognitive Therapy for Depression: Preliminary Evidence from a Randomized Controlled Trial. Int J Cogn Ther 2010, 3(4):402-418. 
92. Garland EL, Farb NA, Goldin P, Fredrickson BL: Mindfulness Broadens Awareness and Builds Eudaimonic Meaning: A Process Model of Mindful Positive Emotion Regulation. Psychol Inq 2015, 26(4):293-314.

93. Farb N, Daubenmier J, Price CJ, Gard T, Kerr C, Dunn BD, Klein AC, Paulus MP, Mehling WE: Interoception, contemplative practice, and health. Frontiers in Psychology 2015, 6:763.

94. Domschke K, Stevens S, Pfleiderer B, Gerlach AL: Interoceptive sensitivity in anxiety and anxiety disorders: An overview and integration of neurobiological findings. Clinical Psychology Review 2010, 30(1):1-11.

95. Ehlers A, Breuer P: Increased cardiac awareness in panic disorder. Journal of Abnormal Psychology 1992, 101(3):371-382.

96. Pollatos O, Traut-Mattausch E, Schandry R: Differential effects of anxiety and depression on interoceptive accuracy. Depression and anxiety 2009, 26(2):167-173.

97. Paulus MP, Stein MB: Interoception in anxiety and depression. Brain structure and Function 2010, 214(5-6):451-463.

98. Schandry R: Heart Beat Perception and Emotional Experience. Psychophysiology 1981, 18(4):483-488.

99. Etkin A, Wager TD: Functional neuroimaging of anxiety: a meta-analysis of emotional processing in PTSD, social anxiety disorder, and specific phobia. The American journal of psychiatry 2007, 164(10):1476-1488.

100. Pitman RK, Rasmusson AM, Koenen KC, Shin LM, Orr SP, Gilbertson MW, Milad MR, Liberzon I: Biological studies of post-traumatic stress disorder. Nat Rev Neurosci 2012, 13(11):769-787.

101. Etkin A: Functional neuroanatomy of anxiety: a neural circuit perspective. Curr Top Behav Neurosci 2010, 2:251-277.

102. Hamilton JP, Chen MC, Gotlib IH: Neural systems approaches to understanding major depressive disorder: an intrinsic functional organization perspective. Neurobiology of disease 2013, 52:4-11.

103. Yuen GS, Gunning-Dixon FM, Hoptman MJ, AbdelMalak B, McGovern AR, Seirup JK, Alexopoulos GS: The salience network in the apathy of late-life depression. International Journal of Geriatric Psychiatry 2014, 29(11):1116-1124.

104. Sripada RK, King AP, Welsh RC, Garfinkel SN, Wang X, Sripada CS, Liberzon I: Neural dysregulation in posttraumatic stress disorder: evidence for disrupted equilibrium between salience and default mode brain networks. Psychosom Med 2012, 74(9):904911.

105. Lutz J, Herwig U, Opialla S, Hittmeyer A, Jancke L, Rufer M, Grosse Holtforth M, Bruhl AB: Mindfulness and emotion regulation--an fMRI study. Soc Cogn Affect Neurosci 2014, 9(6):776-785.

106. Taylor VA, Grant J, Daneault V, Scavone G, Breton E, Roffe-Vidal S, Courtemanche J, Lavarenne AS, Beauregard M: Impact of mindfulness on the neural responses to emotional pictures in experienced and beginner meditators. Neuroimage 2011, 57(4):1524-1533. 
107. Desbordes G, Negi LT, Pace TW, Wallace BA, Raison CL, Schwartz EL: Effects of mindfulattention and compassion meditation training on amygdala response to emotional stimuli in an ordinary, non-meditative state. Front Hum Neurosci 2012, 6:292.

108. Goldin P, Ziv M, Jazaieri H, Hahn K, Gross JJ: MBSR vs aerobic exercise in social anxiety: fMRI of emotion regulation of negative self-beliefs. Soc Cogn Affect Neurosci 2013, 8(1):65-72.

109. Holzel BK, Hoge EA, Greve DN, Gard T, Creswell JD, Brown KW, Barrett LF, Schwartz C, Vaitl D, Lazar SW: Neural mechanisms of symptom improvements in generalized anxiety disorder following mindfulness training. Neuroimage Clin 2013, 2:448-458.

110. Kral TRA, Schuyler BS, Mumford JA, Rosenkranz MA, Lutz A, Davidson RJ: Impact of short- and long-term mindfulness meditation training on amygdala reactivity to emotional stimuli. Neuroimage 2018, 181:301-313.

111. Doll A, Holzel BK, Mulej Bratec S, Boucard CC, Xie X, Wohlschlager AM, Sorg C: Mindful attention to breath regulates emotions via increased amygdala-prefrontal cortex connectivity. Neuroimage 2016, 134:305-313.

112. Taren AA, Gianaros PJ, Greco CM, Lindsay EK, Fairgrieve A, Brown KW, Rosen RK, Ferris $\mathrm{JL}$, Julson $\mathrm{E}$, Marsland AL et al: Mindfulness meditation training alters stress-related amygdala resting state functional connectivity: a randomized controlled trial. Soc Cogn Affect Neurosci 2015, 10(12):1758-1768.

113. Holzel BK, Brunsch V, Gard T, Greve DN, Koch K, Sorg C, Lazar SW, Milad MR: Mindfulness-Based Stress Reduction, Fear Conditioning, and The Uncinate Fasciculus: A Pilot Study. Front Behav Neurosci 2016, 10:124.

114. Holzel BK, Lazar SW, Gard T, Schuman-Olivier Z, Vago DR, Ott U: How Does Mindfulness Meditation Work? Proposing Mechanisms of Action From a Conceptual and Neural Perspective. Perspect Psychol Sci 2011, 6(6):537-559.

115. Kummar AS: Mindfulness and Fear Extinction: A Brief Review of Its Current Neuropsychological Literature and Possible Implications for Posttraumatic Stress Disorder. Psychol Rep 2018, 121(5):792-814.

116. Milad MR, Quirk GJ: Fear extinction as a model for translational neuroscience: ten years of progress. Annu Rev Psychol 2012, 63:129-151.

117. Garfinkel SN, Abelson JL, King AP, Sripada RK, Wang X, Gaines LM, Liberzon I: Impaired contextual modulation of memories in PTSD: an fMRI and psychophysiological study of extinction retention and fear renewal. J Neurosci 2014, 34(40):13435-13443.

118. Newman MG, Lafreniere LS, Jacobson NC: Relaxation-induced anxiety: Effects of peak and trajectories of change on treatment outcome for generalized anxiety disorder. Psychother Res 2018, 28(4):616-629.

119. Hasenkamp W, Wilson-Mendenhall CD, Duncan E, Barsalou LW: Mind wandering and attention during focused meditation: a fine-grained temporal analysis of fluctuating cognitive states. Neuroimage 2012, 59(1):750-760.

120. Lindsay EK, Creswell JD: Mechanisms of mindfulness training: Monitor and Acceptance Theory (MAT). Clinical Psychology Review 2017, 51:48-59.

121. Mennin DS, Fresco DM, Gross JJ: Emotion Regulation Therapy. Guilford Publishers 2014. 
122. Lindsay EK, Chin B, Greco CM, Young S, Brown KW, Wright AGC, Smyth JM, Burkett D, Creswell JD: How mindfulness training promotes positive emotions: Dismantling acceptance skills training in two randomized controlled trials. 2018, 115(6):944. 
Highlights

- We discuss the issues related to distress and challenges to in resolving distress disorders

- We propose that the metacognitive capacity of decentering which is reliably increased by mindfulness-based interventions can increase decentering can resolve distress

- We describe normative neural networks that underlie emotion, cognition, and goal directed behavior

- We review known or hypothesized patterns neural activation and connectivity associated with the components of decentering and how mindfulness-based interventions have been shown or are hypothesized to increase decentering

Conflict Statement:

We wish to confirm that there are no known conflicts of interest associated with this publication and there has been no significant financial support for this work that could have influenced its outcome. We confirm that the manuscript has been read and approved by all named authors and that there are no other persons who satisfied the criteria for authorship but are not listed. We further confirm that the order of authors listed in the manuscript has been approved by all of us. We confirm that we have given due consideration to the protection of intellectual property associated with this work and that there are no impediments to publication, including the timing of publication, with respect to intellectual property. In so doing we confirm that we have followed the regulations of our institutions concerning intellectual property. We understand that the Corresponding Author is the sole contact for the Editorial process (including Editorial Manager and direct communications with the office). $\mathrm{He} /$ she is responsible for communicating with the other authors about progress, submissions of revisions and final approval of proofs. We confirm that we have provided a current, correct email address which is accessible by the Corresponding Author and which has been configured to accept email from (samadhi@med.umich.edu) Signed by all authors as follows: David M. Fresco 6 Dec 2018 Anthony P. King 6 Dec 2018 


\section{Annotated References}

*2. Mennin DS, Fresco DM: Advancing Emotion Regulation Perspectives on Psychopathology: The Challenge of Distress Disorders. Psychological Inquiry 2015, 26(1):80-92.

Conceptual model of distress disorders

*9. Shackman AJ, Tromp DPM, Stockbridge MD, Kaplan CM, Tillman RM, Fox AS:

Dispositional negativity: An integrative psychological and neurobiological perspective. Psychological Bulletin 2016, 142(12):1275.

Important paper reviewing and synthesizing work into the nature of dispositional negativity and related constructs

*10. Ottaviani C, Thayer JF, Verkuil B, Lonigro A, Medea B, Couyoumdjian A, Brosschot JF: Physiological Concomitants of Perseverative Cognition: A Systematic Review and MetaAnalysis. Psychological Bulletin 2015, 142(3):231-259.

Comprehensive review of the effects of negative self-referentiality

**16. Bernstein A, Hadash Y, Lichtash Y, Tanay G, Shepherd K, Fresco DM: Decentering and Related Constructs: A Critical Review and Metacognitive Processes Model. Perspectives on Psychological Science 2015, 10(5):599-617.

Important conceptual paper and integrative review of the extant literature relevant to decentering.

*36. Raichle ME, MacLeod AM, Snyder AZ, Powers WJ, Gusnard DA, Shulman GL: A default mode of brain function. Proc Natl Acad Sci U S A 2001, 98(2):676-682.

Seminal article about the default mode network

*37. Andrews-Hanna JR, Reidler JS, Sepulcre J, Poulin R, Buckner RL: Functional-anatomic fractionation of the brain's default network. Neuron 2010, 65(4):550-562.

Integrative review about the default mode network

**72. Whitfield-Gabrieli S, Ford JM: Default Mode Network Activity and Connectivity in Psychopathology. Annual Review of Clinical Psychology 2012, 8(1):49-76.

Important statement linking the default mode network to emotional disorders

*73. Brewer JA, Worhunsky PD, Gray JR, Tang Y-Y, Weber J, Kober H: Meditation experience is associated with differences in default mode network activity and connectivity. Proceedings of the National Academy of Sciences 2011, 108(50):20254-20259.

Early paper identifying decreased DMN and increased DMN connectovoty with FPCN and SN in long-term meditators compared to well-matched controls 
**47. Kaiser RH, Andrews-Hanna JR, Wager TD, Pizzagalli DA: Large-Scale Network Dysfunction in Major Depressive Disorder: A Meta-analysis of Resting-State Functional Connectivity. JAMA Psychiatry 2015, 72(6):603-611.

Meta-analysis of resting state functional connectivity findings in Major Depressive Disorder

**99. Etkin A, Wager TD: Functional neuroimaging of anxiety: a meta-analysis of emotional processing in PTSD, social anxiety disorder, and specific phobia. Am J Psychiatry 2007, 164(10):1476-1488.

Large meta-analysis of neuroimaging studies in anxiety disorders and PTSD

*100. Pitman RK, Rasmusson AM, Koenen KC, Shin LM, Orr SP, Gilbertson MW, Milad MR, Liberzon I: Biological studies of post-traumatic stress disorder. Nat Rev Neurosci 2012, 13(11):769-787.

Comprehensive overview of neurobiology of PTSD

*97. Paulus MP, Stein MB: Interoception in anxiety and depression. Brain structure and Function 2010, 214(5-6):451-463.

Conceptual paper synthesizing normative and disordered activity of the insula and related neural systems

*18. Farb N, Anderson A, Ravindran A, Hawley L, Irving J, Mancuso E, Gulamani T, Williams G, Ferguson A, Segal ZV: Prevention of Relapse/Recurrence in Major Depressive Disorder With Either Mindfulness-Based Cognitive Therapy or Cognitive Therapy. Journal of Consulting and Clinical Psychology 2017.

Provides an account for how decentering improves treatment of depression

*19. Hoge EA, Bui E, Goetter E, Robinaugh DJ, Ojserkis RA, Fresco DM, Simon NM: Change in Decentering Mediates Improvement in Anxiety in Mindfulness-Based Stress Reduction for Generalized Anxiety Disorder. Cognitive Therapy and Research 2015, 39(2):228-235.

$\mathrm{MBI}$ showing the relationship of a gains in decentering to clinical improvement

*20. Segal ZV, Anderson AK, Gulamani T, Williams L-AD, Desormeau P, Ferguson A, Walsh K, Farb NAS: Practice of therapy acquired regulatory skills and depressive relapse/recurrence prophylaxis following cognitive therapy or mindfulness based cognitive therapy. Journal of Consulting and Clinical Psychology 2018.

Provides an account for how decentering improves treatment of depression

**26. Vago DR, Silbersweig DA: Self-awareness, self-regulation, and self-transcendence (SART): a framework for understanding the neurobiological mechanisms of mindfulness. Frontiers in Human Neuroscience 2012, 6:296.

Important conceptual model of the neurobehavioral underpinnings of meditation training 
*52. Gotink RA, Meijboom R, Vernooij MW, Smits M, Hunink MG: 8-week Mindfulness Based Stress Reduction induces brain changes similar to traditional long-term meditation practice - A systematic review. Brain Cogn 2016, 108:32-41.

Review identifying MBSR-linked increases in activity, connectivity and volume in PFC, cingulate, insula and hippocampus that are similar to findings in long-term meditators

*29. Hasenkamp W, Barsalou LW: Effects of meditation experience on functional connectivity of distributed brain networks. Front Hum Neurosci 2012, 6:38.

Further eamined functional connectivity in DMN, SN, and FPCN ROI seeds in the meditation decomposition study belwo

**119. Hasenkamp W, Wilson-Mendenhall CD, Duncan E, Barsalou LW: Mind wandering and attention during focused meditation: a fine-grained temporal analysis of fluctuating cognitive states. Neuroimage 2012, 59(1):750-760.

A clever $\mathrm{fMRI}$ study temporally decomposing elements of focussed attention meditation practice using self-report (button press) of awareness of mind-wandering in the meditator, identifying activations in $\mathrm{DMN}$ in mind andering, $\mathrm{SN}$ in shifting attention, and exectuive and attention newtorks in sustained focus.

*31. Vago DR, Zeidan F: The brain on silent: mind wandering, mindful awareness, and states of mental tranquility. Ann N Y Acad Sci 2016, 1373(1):96-113.

Important mechanistic review of neurobiology of mindfulness practices and mind-wandering, including brain connectivity networks

**59. Tang YY, Lu Q, Geng X, Stein EA, Yang Y, Posner MI: Short-term meditation induces white matter changes in the anterior cingulate. Proc Natl Acad Sci U S A 2010, 107(35):1564915652.

Early paper demonstrating structural changes in ACC after 5 days of traniing

*70. Northoff G, Bermpohl F: Cortical midline structures and the self. Trends Cogn Sci 2004, 8(3):102-107.

Important review of self and self-realted processing

*79. Creswell JD, Taren AA, Lindsay EK, Greco CM, Gianaros PJ, Fairgrieve A, Marsland AL, Brown KW, Way BM, Rosen RK et al: Alterations in Resting-State Functional Connectivity Link Mindfulness Meditation With Reduced Interleukin-6: A Randomized Controlled Trial. Biol Psychiatry 2016, 80(1):53-61.

Replication of increased PCC-dIPFC functional connectivity in healthy people following 3-days intensive meditation

*80. King AP, Block SR, Sripada R, Rauch SA, Giardino ND, Favorite T, Angstadt M, Liberzon I: Altered Default Mode Network (DMN) Resting State Functional Connectivity Following a Mindfulness-based Exposure Therapy for Posttraumatic Stress Disorder (PTSD) in Combat Veterans of Afghanistan and Iraq. Depression and Anxiety 2016 
Replication of increased PCC-dIPFC functional connectivity in PTSD patients following 16 weeks of Mindfulness-based Exposure Therapy (based on MBCT)

*84. Andrews-Hanna JR, Saxe R, Yarkoni T: Contributions of episodic retrieval and mentalizing to autobiographical thought: evidence from functional neuroimaging, resting-state connectivity, and fMRI meta-analyses. Neuroimage 2014, 91:324-335.

Identifies difference in DMN subsystems in autobiographical memories in recall vs mentalinzg

*86. Farb NA, Segal ZV, Anderson AK: Mindfulness meditation training alters cortical representations of interoceptive attention. Soc Cogn Affect Neurosci 2013, 8(1):15-26.

Probes effects of MBSR on connectivity of dmPFC (DMN) and insula (SN) during interoception

**113. Holzel BK, Brunsch V, Gard T, Greve DN, Koch K, Sorg C, Lazar SW, Milad MR: Mindfulness-Based Stress Reduction, Fear Conditioning, and The Uncinate Fasciculus: A Pilot Study. Front Behav Neurosci 2016, 10:124.

Fascinating pilot study using sophisticated 2-day fear conditioning / extinction memory paradigm; suggesting mindfulness practice might improve strength of extinction recall by increasing connectivity in uncinate fasiculus. Small sample size and heterogenity of sample at intake confounded interpreatation, but very exciting pilot data that hopefully will be replicated in a larger and more homogenous sample soon.

*114. Holzel BK, Lazar SW, Gard T, Schuman-Olivier Z, Vago DR, Ott U: How Does Mindfulness Meditation Work? Proposing Mechanisms of Action From a Conceptual and Neural Perspective. Perspect Psychol Sci 2011, 6(6):537-559.

Important review of psychological and neurobiological findings in mindfulness and theoretical account of potential mechanisms

*57. Tang YY, Holzel BK, Posner MI: The neuroscience of mindfulness meditation. Nat Rev Neurosci 2015, 16(4):213-225.

Important review of psychological and neurobiological findings in mindfulness and theoretical account of potential mechanisms

*50. Liberzon I, Abelson JL: Context Processing and the Neurobiology of Post-Traumatic Stress Disorder. Neuron 2016, 92(1):14-30.

Reviews neurobiological mechanisms of PTSD and proposed dysfunctional contextual processing as a central mechanism

*109. Holzel BK, Hoge EA, Greve DN, Gard T, Creswell JD, Brown KW, Barrett LF, Schwartz C, Vaitl D, Lazar SW: Neural mechanisms of symptom improvements in generalized anxiety disorder following mindfulness training. Neuroimage Clin 2013, 2:448-458.

Identifies potential neural correlates of effects of MBSR on GAD using pre-post fMRI and group $x$ time interaction analyses 
*120. Lindsay EK, Creswell JD: Mechanisms of mindfulness training: Monitor and Acceptance Theory (MAT). Clinical Psychology Review 2017, 51:48-59.

Important contemporary intervention model with sequenced mindfulness interventions

*121. Mennin DS, Fresco DM, Gross JJ: Emotion Regulation Therapy. Guilford Publishers 2014. Important psychotherapy imbued with mindfulness practices with efficacy for distress disorders 